\title{
Optimization of Physical Distribution of Consumer Goods in Nigeria: A Case Study of Unilever. Nigeria Plc (South-East Region).
}

\author{
Okeudo Geraldine \\ Department Of Transport Management Technology,Federal University Of Technology, Owerri.
}

\begin{abstract}
The study is aimedat procuring optimalsolutions to challenges faced in the physical distribution system of consumer goods in Nigeria context also the need to minimize cost especially in Physical distribution is inevitable as increased cost of transport and poor transport infrastructure imposes strain on the physical distribution system. The researcher applied network optimization models to develop optimal solutions to real life problems in physical distribution system. Using questionnaires the researcher was able to explain how various service variables influence the service level.The researcher identified trends in warehousing operations, the nature of the relationship between physical flow and distribution cost and how various service variables influenced the service level. Afterwards, he recommended ways to benefit from these opportunitiesand steps to take to cub the impact of its challenges of the physical distribution system.
\end{abstract}

Keywords: Warehouse, Physical distribution system, network optimization, distribution channel, physical flow.

\section{Introduction}

Production is the creation of goods and services, these goods and services can be produced in factories or industries and stored in warehouses. However, production cannot to be said to be complete until the products/services get to end user or consumer. This can be obtained through the distribution process and that complete the production cycle. The distribution activity is equally referred to as physical distribution management (PDM), marketing logistics or physical flow. Physical distribution is the collective term for series of inter-related functions (primarily transportation, stockholding, storage, goods handling and order processing) involved in the physical transfer of finished goods form producer to consumer, directly or through intermediaries.

Physical distribution explains the problem of getting the right quantity of the right product to the right place at the right time and at the least cost possible, this problem has confronted companies with challenges like meeting delivery due dates and operating an efficient distribution network. Companies like consumer goods companies, with their great diversity of customers spread over vast geographical areas must integrate the systems components of distribution to achieve an acceptable customer service level and avoid reduction of market share(Bowersox, 1978). Geographical imposed gap between firms and their potential consumers is bridged by distribution, as physical distribution uses its transportation function to provide time and space utility between these two parties (Bowersox and Closs, 1996). The continuous increase in the cost of transportation due to poor nature of our roads, high cost of vehicles and spare parts and currently increase in cost of petroleum products poses a serious problem to an effective coverage of territories in the distribution both in rural and urban areas in the country.

Distribution is becoming a more imperative issue in company accounts as the cost of transport, warehousing and stockholding were growing relative to the costs of other industrial inputs. Marketing efforts, such as the extension of product lines and penetration of new marketing channels into new markets, were imposing increasing strain on distribution systems, making them more complex to manage and more expensive to operate(McKinnon, 1999). Contemporary firms has reorganised their distribution systems to take advantage of the major improvements that was made in the transport and storage infrastructure. The introduction of information management system (IMS) has greatly eased order processing, resource allocation and analysis of distribution cost which has promoted the application of operations research techniques in distribution planning. In the emergence of these marginal problems and the fact that there are so many brands of consumer goods in the market from which the consumer has to choose with little or no attention to difference among them in terms of quality and other characteristics. The consumer goods market which is characterizedby low brand loyalty, has made the market as highly volatile which is driven by availability and price rather than marketing efforts and quality(Cooper and Johnstone, 1990). It then discloses that there is a need for the consumer goods companies to manage the physical distribution system and engage in proper manipulation of other functional trade-offs in the system in order to breakeven in the present day competitive consumer goods market in Nigeria. 


\subsection{Statement Of Research Problem}

Distribution firms have always researched for methods to minimise the cost and maximise flow of shipping each unit of commodity to and fro across the supply and demand nodes. Though, warehousing has smoothen out the fluctuations in demand and supply at market place yet major constraints are been faced in assigning supply and properly matching orders placed during redistribution to final retailers outlets. In recent times logistics firms are faced with greater problems of optimizing the whole system so as to develop strategies that minimizes cost and maximizes flow. This is because optimization helps to minimize shadow costs incurred which cannot be objectively determined by conventional accounting methods such as cost of losing a customer form a delayed delivery. The above scenario results in an operations research problem called maximum flow and minimum cost network problem. Firms tend to find solutions to the following:

i. Efficiently utilize space, resources and capacity of warehouses that will be optimal to avoid diseconomies of scale from under-utilization of warehouses.

ii. Allocation of the flow of products and balancing of routes from each salesman to retailers' outlets.

iii. Setting geographical coverage area for each warehouse to avoid conflicting customer coverage.

iv. To determine the optimal distribution cost that efficient sustains the distribution system given the firm's delivery policies and plans.

With the problem already mentioned above, This study is to reduce cost of physical flow of products and optimize the physical distribution system from distribution centres to wholesalers and retail outlets.

Other objectives include:

1. Determine the shortest sales path that minimizes the total travel time and supports an effective sales coverage.

2. Determine the optimal workload of each route, which justifies the cost of distribution.

\section{1dimensions of physical Distribution}

\section{Review of Related Literature.}

The distribution process begins when a supplier receives an order from a customer. The customer is not too concerned with the design of the supplier's distributive system, nor in any supply problems. In practical terms, the customer is only concerned with the efficiency of the supplier's distribution. That is, the likelihood of receiving goods at the time requested. Lead-time is the period of time that elapses between the placing of an order and receipt of the goods. This can vary according to the type of product and the type of market and industry being considered. Lead-time in the shipbuilding industry can be measured in fractions or multiples of years, whilst in the retail sector, days and hours are common measures. Customers make production plans based on the lead-time agreed when the order was placed. Customers now expect that the quotation will be adhered to and a late delivery is no longer acceptable in most purchasing situations.

PDM is concerned with ensuring that the individual components efforts that go to make up the distributive function are optimised so that a common objective is realised. This is called the 'systems approach' to distribution management and a major feature of PDM is that these functions be integrated. These functions include;

- Order processing

- Stock levels or inventory

- Warehousing

- Transportation

In explaining the systems approach to distribution management there are two central themes that should be taken into account:

1. The success of an efficient distribution system relies on integration of individual component effort. An overall service objective can be achieved, even though it may appear that some individual components of the system are not performing at maximum efficiency.

2. It is never possible to provide maximum service at a minimum cost. The higher the level of service required by the customer, the higher the cost. Having decided on the necessary level of service, a company must then consider ways of minimising costs, which should never be at the expense of a reduction of the predetermined service level.

\subsubsection{Order processing}

The efficiency of order processing has a direct effect on lead times. Orders are received from the sales team through the sales department. Many companies establish regular supply routes that remain relatively stable over a period of time providing that the supplier performs satisfactorily. Order-processing systems should function quickly and accurately. Other departments in the company need to know as quickly as possible that an order has been placed and the customer must have rapid confirmation of the order's receipt and the precise delivery time. Even before products are manufactured and sold the level of office efficiency is a major 
contributor to a company's image. Incorrect documentation and slow response by the sales team are often an unrecognised source of ill-will between buyers and sellers. When buyers evaluate their suppliers, efficiency of order processing is an important factor in their evaluation.Anefficient computer system for order processing allows stock levels and delivery schedules to be automatically updated so management can quickly obtain an accurate view of the sales position. Accuracy is an important objective of order processing as are procedures that are designed to shorten the order processing cycle.

\subsubsection{Inventory}

Inventory management is a critical area of PDM because stock levels have a direct effect on levels of service and customer satisfaction. The optimum stock level is a function of the type of market in which the firm operates. Few companies can say that they never run out of stock, but if stock-outs happen regularly then market share will be lost to more efficient competitors. The key lies in determining the re-order point. Carrying stock at levels below the re-order point might ultimately mean a stock-out, whereas too high stock levels are unnecessary and expensive to maintain. The stock/cost dilemma is clearly illustrated by the systems approach to PDM.

Stocks represent opportunity costs that occur because of constant competition for the company's limited resources. If the company's marketing strategy requires that high stock levels be maintained, this should be justified by a profit contribution that will exceed the extra stock carrying costs. Sometimes a company may be obliged to support high stock levels because the lead-times prevalent in a given market are particularly short. In such a case, the company must seek to reduce costs in other areas of the PDM 'mix'.

\subsubsection{Warehousing}

American marketing texts tend to pay more attention to warehousing than British texts do. This is mainly because of the relatively longer distances involved in distributing in the USA, where it can sometimes take days to reach customers by the most efficient road or rail routes. Currently, many companies function adequately with their own on-site warehouses from where goods are dispatched direct to customers. When a firm markets goods that are ordered regularly, but in small quantities, (such as consumer goods companies) it becomes more advisable to locate warehouses strategically around the location. Transportation can be carried out in bulk from the place of manufacture to respective warehouses where stocks wait ready for further distribution to the customers. This system is used by large retail chains, except that the warehouses and transportation are owned and operated for them by third parties. Levels of service will of course increase when numbers of warehouse locations increase, but cost will increase accordingly. So, an optimum policy must be established that reflects the desired level of service.

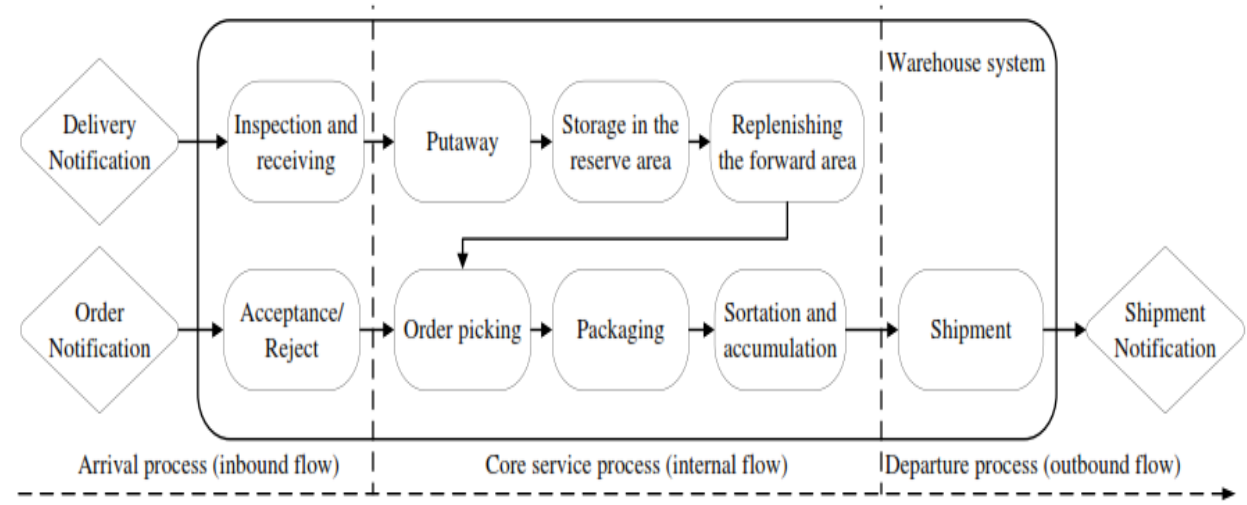

Figure 1.0.The above chart shows a typical warehouse operation

Source: Gong, Y. (2009). Stochastic Modelling and Analysis of Warehouse Operations. (E. R. Management, Ed.) Rotterdam, Netherland.

\section{METHODOLOGY.}

\section{Methodology}

In sourcing for relevant information for this research, the primary data and secondary data were sourced from respondents by the administration of questionnaires to the respondents, personal observations of various geographical locations. The questions were structured for easy understandings by the respondents to enable them give the appropriate responses. The secondary data source of information in this study was the review of internal databases so as to get the required information on SKU history, sales out and stock received. The time span of all the data generated from the internal databases was six months. The major problem 
encountered, were the data descriptions in the database that did not use conventional descriptions for security reasons; the researcher had to reorganize the data descriptions for better understanding.

\subsection{SAMPLING}

The sampling frame of the research consists of a very large population which consists of all warehouse and Unilever retailers in South-east, Nigeria. A total of 107 questionnaires were dispatched to the retailers in the two locations selected. A total of 101 questionnaires were returned 50 from Onitsha location and 51 form Owerri location.The samples in this research were based on non-probability samples, but this has little connection to the use of purposive sampling. Instead, this reliance on the use non-probability samples is due to the difficulty of locating data sources that meet eligibility criteria and counting the total size of the population from which that sample is drawn. In addition, the need to collect detailed, in-depth data typically leads to small sample sizes where there would be no point to doing statistical analysisOnitsha and Owerri locations were the samples chosen from the South-east ${ }^{[21]}$ population. The reason was to reduce the cost of research yet achieving a reasonable research data accuracy and reliability of research results.

\subsection{Analytical Tool Utilised.}

In this study the network optimization model analysis was utilized to determine the shortest sales path that minimizes the total travel time and supports an effective sales coverage and to determine the optimal workload of each route, which justifies the cost of distribution.

\subsubsection{Network Optimization Models}

A scenario of a network flow problem that arises in physical distribution concerns the distribution of heterogeneous products from warehouses (origins) to retailer's outlets (destinations). The total number of shipments supplied to each warehouse and the total number of shipments required at each market are assumed to be known. The product need not be sent directly from source to destination, but may be routed through intermediarypoints reflecting other demand points. Further, there may be capacity restrictions that limit flow in the shipping links. The objective is to maximise flow and minimize the variable cost of shipping theproducts to meet the consumer demand (Hillier and Lieberman, 2001).

The sources, destinations, and intermediate points are collectively called nodes of the network, and thetransportation links connecting nodes are termed arcs. The nodes are represented by numbered circles and the arcs by arrows. Figure shows a typical distribution network for a warehouse. Node 1 is the warehouse while nodes 2 to nodes 10 are the retailer's outlet that the salesman has to visit on specified iterations a least for a one day trip.

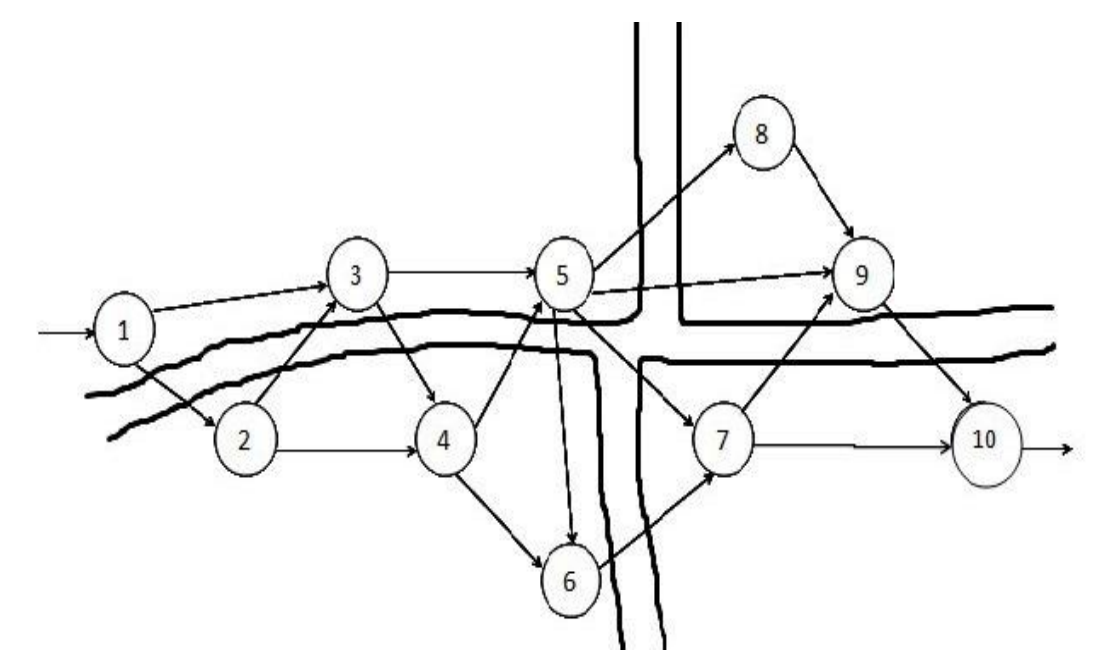

Figure 1.0.The above network shows a typical physical distribution network of a warehouse.

The researcher is then be concerned with the capacityof the network and tries to solve the problem of "how much units can be sent from a supply node to the demand node?" the model explains defines the problem using the maximum flow problem.

$x_{i j}=$ flow through arc $i \rightarrow j$

$c_{i j}=$ cost per unit flow through arc $i \rightarrow j$

$b_{i}=$ net flow generated at node $i$ 
$u_{i j}=\operatorname{arc}$ capacity for $\operatorname{arc} i \rightarrow j$

The value of $b_{i}$ depends on the nature of node $i$, where,

$b_{i}>0$, node is a supply node

$b_{i}<0$, node is a demand node

$b_{i}=0$, node is a transhippment node

Since, the optimal objective is to minimize the total cost and maximise flow of the available supply through thenetwork to satisfy the given demand at the retail outlets.By using the convention that summations are taken only over existing arcs, the linearprogramming formulation of this problem is;

Minimize $Z=\sum_{i} \cdot \sum_{j} \mathrm{c}_{i j} x_{i j}$

Subject to,

$\sum_{i=1}^{n} x_{i j}-\sum_{j=1}^{n} x_{j i}=b_{i}$, for each node $i$

and,

$o \leq x_{i j} \leq u_{i j}, \quad$ for each arc $i \rightarrow j$

To obtain a feasible solution, the condition $\sum_{i=0}^{n} b_{i}=0$ is a necessary condition to attain feasible solutions a minimum cost flow problem.

The researcher solved the network optimization problem by using the Network Solver Microsoft Excel add-in of the JensenORMM (Operations Research Models \& Methods) add-ins by Paul A. Jensen of Operations Research Group, University of Texas, USA. The add-ins were used due to its ability to solve a large array of operations research problems in a single sheet and made the inferences of the results.

\section{Data Analysis}

For the purpose of this study an assumed distribution network was developed that can be used to simulate real life nature of a typical distribution network of a regular Unilever warehouse.

Table 1.0.The above table describes a typical sales plan for a salesman

\begin{tabular}{|r|l|l|r|}
\hline S/N & NAME OF RETAIL OUTLET & ADDRESS & $\begin{array}{c}\text { EST.ABV } \\
(\mathbf{0 0}) \text { - } \mathbf{-} \text { - }\end{array}$ \\
\hline 1 & IKEMELO STORE & SAM MBAKWE AVE. BY AKAJIAKU EST. & 35 \\
\hline 2 & MAMA UCHE STORE & I LANE NWANKWO STR. BY CONTROL & 30 \\
\hline 3 & HOME CARE SUPERMARKET & I LANE NWANKWO STR. BY CONTROL & 35 \\
\hline 4 & RICH CAN STORE & 1 PORT HARCOURT RD BY A.P FILLING STATION & 40 \\
\hline 5 & UB SUPER STORES & 5 PORT HARCOURT RD & 30 \\
\hline 6 & JOY ABBAS & 25 PORT HARCOURT RD & 30 \\
\hline 7 & HEARTLAND SUPER STORES & 26 PORT HARCOURT RD & 45 \\
\hline 8 & DIRECTBUY SUPERMARKET & 27 PORT HARCOURT RD & 35 \\
\hline 9 & OKECHUKWU STORE & 27 PORT HARCOURT RD & 20 \\
\hline
\end{tabular}

EST. ABV -- estimated Average Bill Value = demand at retail points evaluated in average purchasing power

Source: Unilever Statistical report 2012.

Table1.0 shows the demand $b_{i}$ at each node and the supply the warehouse has allocated to these set of retailers. All arcs in the network have been assigned a numbers which starts at arc 1 and ends at arc 17. Table shows the arc characteristics of each arc. Each arc has an assigned flow $x_{i j}$, which is the define routing of in the salesman journey plan. $u_{i j}$ is the capacity at each arc which is defined by in range of a lower and upper limit. In this case a capacity on each node can be defined by the vehicle or carriage unit assigned to that node. The corresponding distribution cost $c_{i j}$ for each arc, is cost required to shipped flows between nodes in the network, it is dependent on the distance and carriage unit assigned to that arc. Assuming we use the estimated average billing value to be the demand at each the demand nodes. 


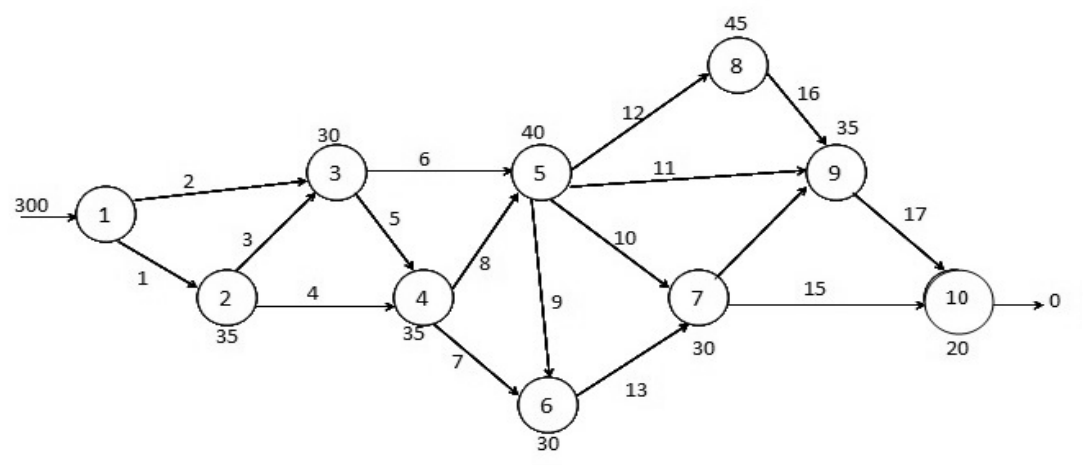

Figure2.0 The distribution network showing the demand at each node and number of arcs.

Table 2.0 The characteristics of the nodes in the network

\begin{tabular}{|c|c|c|c|c|}
\hline \multirow{2}{*}{$\underset{\text { Are }}{\text { Name }}$ of } & \multirow[b]{2}{*}{ Flow $\left(\mathbf{X}_{\mathbf{i} j}\right)$} & \multicolumn{2}{|c|}{ Capacity (Uni.j) } & \multirow{2}{*}{$\begin{array}{c}\text { Cost/umi } \\
t\left(C_{i . j}\right)\end{array}$} \\
\hline & & Lower limit & Upper limit & \\
\hline Arc 1 & 150 & $\mathrm{O}$ & 150 & 750 \\
\hline Arc2 & 150 & $\mathbf{O}$ & 150 & 750 \\
\hline $\operatorname{Arc} 3$ & 115 & $\mathbf{O}$ & 120 & 600 \\
\hline Arc 4 & $\mathbf{O}$ & $\mathbf{O}$ & 120 & 600 \\
\hline Ares & 125 & $\mathbf{O}$ & 120 & 600 \\
\hline ArcG & $\mathbf{O}$ & $\mathbf{O}$ & 120 & 600 \\
\hline Arc 7 & $\mathbf{O}$ & $\mathbf{O}$ & 100 & 500 \\
\hline Arc 8 & 80 & $\mathbf{O}$ & 100 & 500 \\
\hline Arce & $\mathbf{O}$ & $\mathbf{O}$ & 45 & 225 \\
\hline Arcio & 50 & $\mathbf{O}$ & 45 & 225 \\
\hline Arc 11 & 35 & $\mathbf{O}$ & 45 & 225 \\
\hline Arcl 2 & 45 & $\mathbf{O}$ & 45 & 225 \\
\hline $\operatorname{Arc13}$ & $\mathbf{O}$ & $\mathbf{O}$ & 50 & 250 \\
\hline $\operatorname{Arc14}$ & $\mathbf{O}$ & $\mathbf{O}$ & 20 & 100 \\
\hline Arc 15 & 20 & $\mathbf{O}$ & 20 & 100 \\
\hline Arc 16 & $\mathbf{O}$ & $\mathbf{O}$ & 20 & 100 \\
\hline Arci 7 & $\mathbf{O}$ & $\mathbf{O}$ & 20 & 100 \\
\hline
\end{tabular}

\subsubsection{Developing the Shortest path}

The researcher has to develop the shortest path in order to determine the shortest and most efficient route to the retailer's outlet. Using the Jensen ORMM add-in the results are as flows.

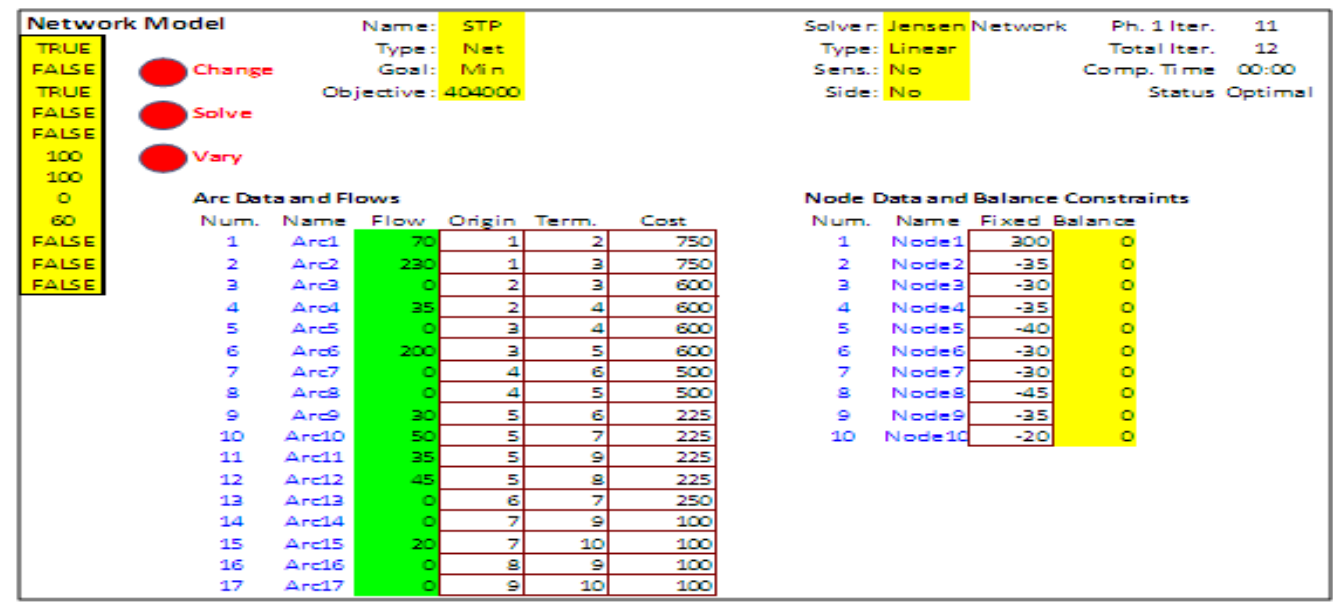

Figure 3.0.The Jensen ORMM results for the shortest path for the network.

The above Figure 3.0 shows an optimal result of the short path. The below figure gives a pictorial perception of the short paths developed. 


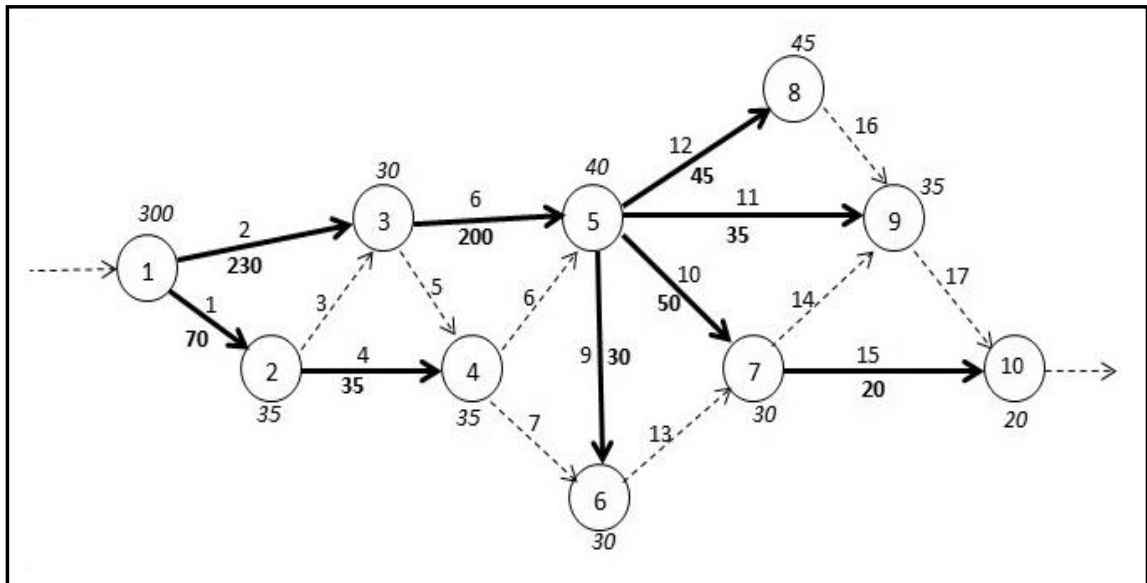

Figure 4.0 the short paths developed in the network.

\subsubsection{Developing the minimum cost for the iterations}

The Jensen ORMM add-in developed four separate iterations for the network which are as follows:

Iteration $1=1 \rightarrow 4$

Iteration $2=2 \rightarrow 6 \rightarrow 9$

Iteration $3=2 \rightarrow 6 \rightarrow 10 \rightarrow 15$

Iteration $4=2 \rightarrow 6 \rightarrow 12$

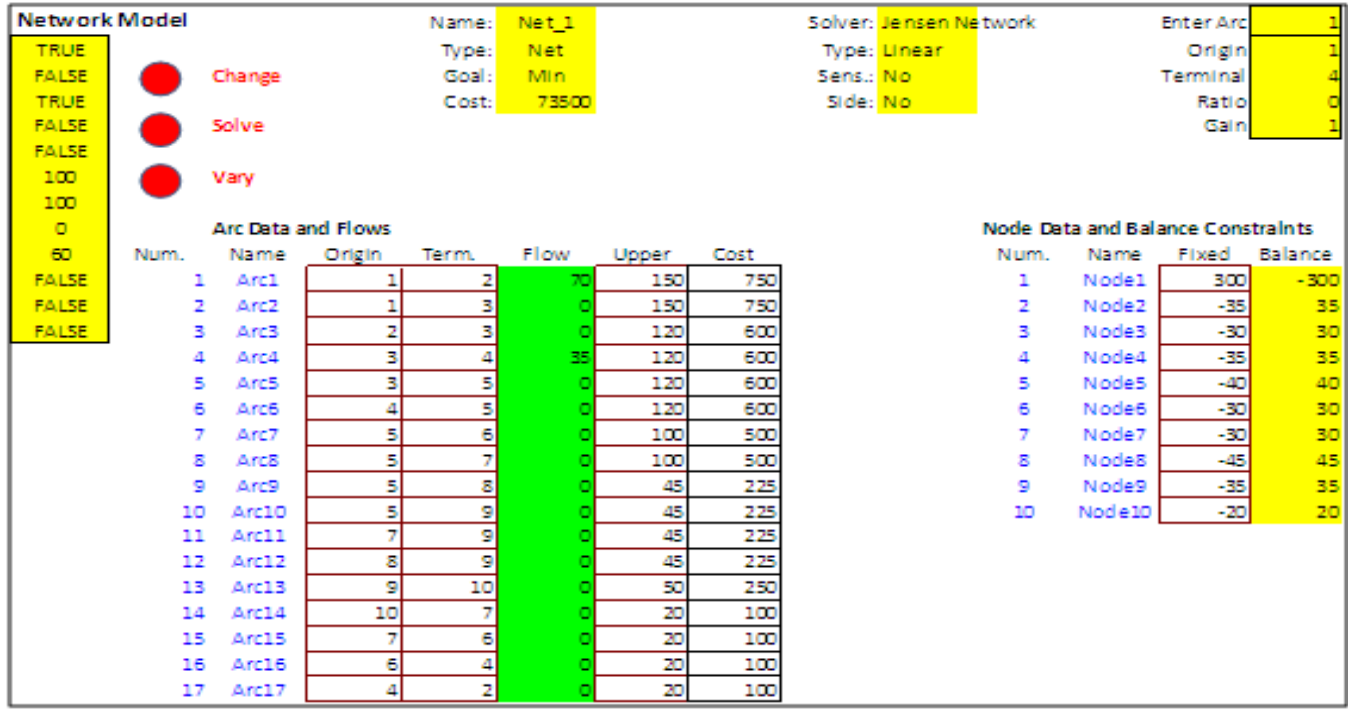

Figure 5.0 .Minimum cost solution for iteration 1

From the optimal solution in figure 5.0 above, shows that Iteration 1 will incure a minimum cost of 773,500. The Jensen ORMM add-in goes on the find optimal solutions for the various iterations which as follows

\begin{tabular}{|l|l|r|}
\hline Ite ration & \multicolumn{1}{|c|}{$\begin{array}{c}\text { Direction of } \\
\text { iteration }\end{array}$} & \multicolumn{1}{c|}{ Cost } \\
\hline Iteration 1 & $1 \rightarrow 4$ & 73,500 \\
\hline Iteration 2 & $2 \rightarrow 6 \rightarrow 9$ & 299,250 \\
\hline Iteration 3 & $2 \rightarrow 6 \rightarrow 10 \rightarrow 15$ & 305,750 \\
\hline Iteration 4 & $2 \rightarrow 6 \rightarrow 12$ & 302,625 \\
\hline & TOTAL & $\mathbf{9 8 1 , 1 2 5}$ \\
\hline
\end{tabular}

Though iteration 1 is the cheapest iteration does not mean it is most effective for and optimal coverage because it does not incorporated all nodes in the network. The supplier may not achieve his ultimate goal of servicing all his customers. The solution to this problem is to develop a minimum spanning tree problem. The minimum spanning tree will be summary of all the iterations into a single iteration which illustrated in Figure 6.0 .below. 


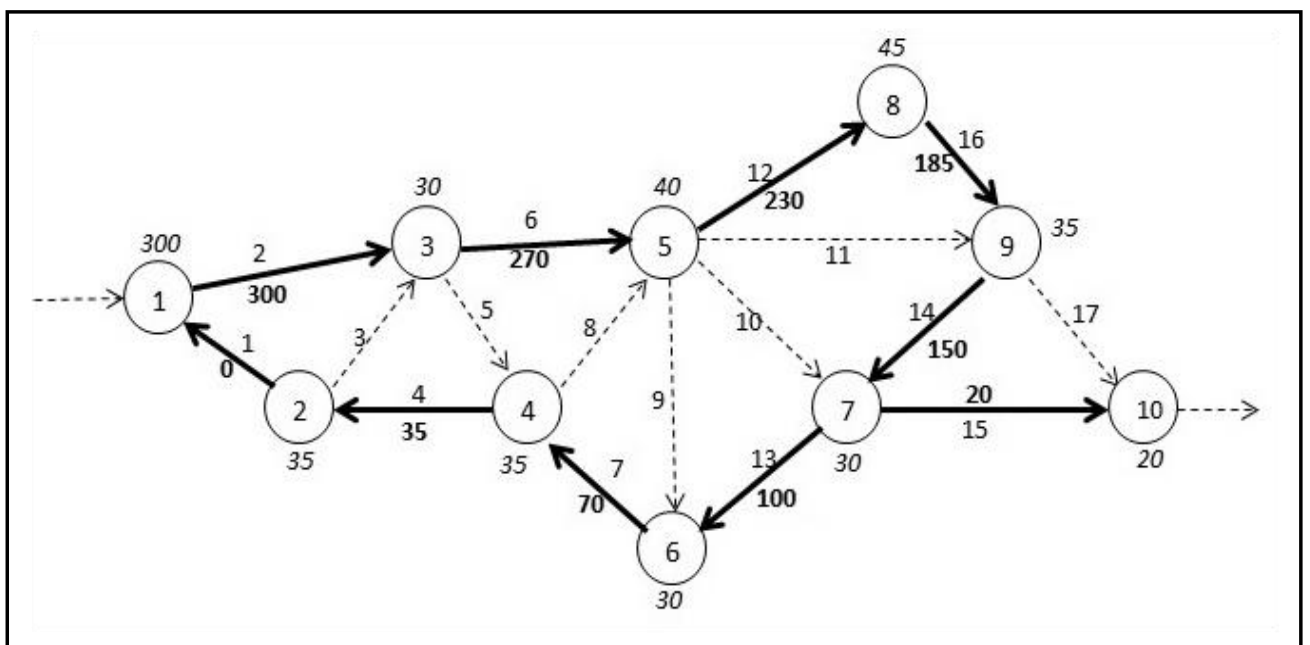

Figure 6.0 .The minimum spanning solution to the network

Figure 6.0.Shows the resultant minimum cost of the minimum spanning solution which is $\$ 555,250$ compared to that of $\$ 981,125$ of the formal optimal solution solved. The warehouse will make savings $\$ 425,875$. This can give the warehouse a platform to make more profit yet meet supply demands from their retailers. Also the warehouse will only have to use one vehicle for a high capacity ( $u_{i j}=300$ for all arcs) to service of demand points.

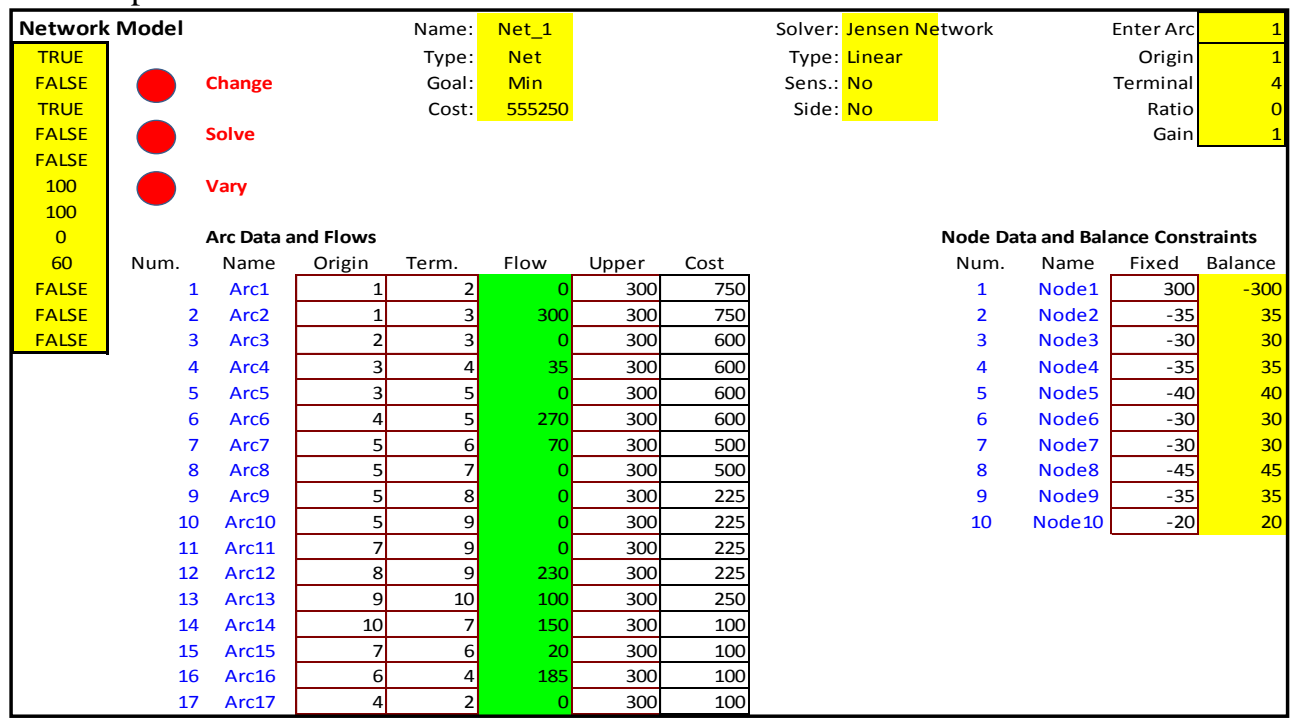

Figure 7.0 .Jensen ORMM minimum cost solution for the minimum spanning tree.

\section{Summary /Conclusion}

The study was driven by the desire to inquire into the cause of failure in the distribution system of most consumer goods companies. Despite the menace of bad and ever increasing price of service factors (like fuel, labour, vehicles) distribution companies have to make profit for it to survive. In achieving this, firms are faced with the challenge of making trade-offs between the price for products in response to increasing cost of service and their market share.

For an optimal physical distribution system to be fully implemented the operations at the source, which is the warehouse has to assessed so as to find loop holes that has to be given attention. The study tried to develop a prototype that can be used to optimize the physical flow of product distribution.

The empirical case study showed that many of the tools and techniques presented in the distribution design framework can be useful when planning and organizing redistribution operations . Reducing cycle time increases the responsiveness and flexibility of a distribution network but requires identifying bottlenecks in the warehousing and distribution processes and finding ways to streamline materials handling, order picking activities and delivery. This implies that management needs to carefully consider the costing structure of these services before they are offered to the customers. It is also worth considering whether value added activities can 
be completely removed from the order processing and redistribution functions, for example, by moving them to be handled by a separate entity in the warehouse or integrate the functions into one whole.

\section{Bibliography}

[1]. (n.d.). The Nigerian Consumer Space: How large in the market? Lagos: BGL Research and Intelligence.

[2]. Ackerman, K.B.,(1997)Practical handbook of warehousing. 4th Edition. Springer.

[3]. Aminoff, A.,Kettunen, O. \&Pajunen-Muhonen, H. (2002) Research on Factors AffectingWarehousingEfficiency.International Journal of Logistics.(5)1 p. 45-57.

[4]. Bowersox, D.J., (1978) Logistical management, 2nd edn. New York: Macmillan.

[5]. Bowersox, D.J. and D.J. Closs (1996) Logistical management: The integrated supply chain process. NewYork: Macmillan.

[6]. Bunus, L.D. Hall , R.W Blumenfeid, D.E. and DaganzoC.F. (1985) Distribution Strategies that minimizetransportation and Inventory costs. Operations Research, (33) 469-490.

[7]. Cooper, J.C., (1993) "Logistics strategies for global businesses", International Journal of PhysicalDistribution and Logistics Management, 24:12-23.

[8]. Cooper, J.C. and M. Johnston (1990) "Dedicated contract distribution: An assessment of the UKmarket place", International Journal of Physical Distribution and Logistics Management, 20:25-31.

[9]. Cooper, C.L. \&Mulaik, S. (2010) Warehouse Activity Profiling - Identifying ImprovementOpportunities in Your Warehouse Operations.The Progress Group, LLC.

[10]. Cooper, M., D.E. Innis \& P.R. Dickson, (1992) Strategic planning for logistics. Oak Brook, IL: Councilof Logistics Management.

[11]. Christopher, M and Peck, H (2003) Marketing Logistics, 2nd edition, ButterworthHeinemann, Oxford.

[12]. Christopher, M. 2005. Logistics \& Supply Chain Management: Creating value-addingnetworks. 3rd Edition. Pearson Education

[13]. Christopher, Martin (1998) Logistics and Supply Chain Management (2.ed.) London: Financial Times/Prentice Hall.

[14]. Crainic, G.T. (2002) (ed): "A survey of optimization models for Long-Haul freight Transportation"Handbook of Transportation Science. R.W. Hall 2 Edition, Kluwer, U.S.A, 102-122.

[15]. Drake, P. P. (n.d.). Regression step-by-step in Excel. James Madison University.

[16]. Fabbes-Costes, N. and J. Colin (1999), "Formulating logistics strategy", in: D. Waters, ed., Globallogistics and distribution planning: Strategies for management, 3rd edn. London: Kogan Page.

[17]. Frederick, H., \& Gerald, L. (2001). Introduction to Operations Research.McGraw-Hill Series.

[18]. Gattorna, J L (1990) Handbook of Logistics and Distribution Management, $4^{\text {th }}$ edn, Gower, Aldershot.

[19]. Gong, Y. (2009). Stochastic Modelling and Analysis of Warehouse Operations. (E.R. Management, Ed.) Rotterdam, Netherland.

[20]. Gu, J. \&Goetschalckx, M. \& McGinnis, L. (2007) Reasearch on warehouse operation: Acomprehensive review. European Journal of Operational Research.Vol. 177, No. 1.p. 121.

[21]. Gunasekaran, A., Patel, C. \&McGaughey, R.E. (2004) A framework for supply chain performance measurement.Production Economics.Vol. 87, No. 3. p. 333-347.

[22]. Given, L. M. (2008). The SAGE Encyclopedia of quantitative research methods. Los Angeles: Sage Publications.

[23]. Kotler, Ph., Strategic Marketing Management, Ed.Teora, Bucuresti, 1997, p. 661

[24]. John, R., Sastry, P., \& David, D. (1998 ). Applied Regression Analysis: a research tool (2nd ed.). New York, USA: Springer-Verlag New York, Inc. Lambert, D. and J.R. Stock (1993) Strategic logistics management, 3rd edn. Irwin, CA: Homewood

[25]. Lambert, D.M. and Stock J.R.Ellram, L.M. (1998):Fundamental of Logistics Management: NewYork: Irwin McGraw-Hill

[26]. Lau, H.C.W., and Lee, W.B. (2000). “On a responsive Supply Chain Information System.” International Journal of Physical Distribution \& Logistics Management, 30 (7/8), Pp. 598-610.

[27]. Philip,K.(1991)_Marketing Management: Analysis, Planning, Implementation, and Control" 7th Edition, Englewood Cliffs, NJ: Prentice-Hall.

[28]. Manila.Ho, J.K. (1997). What can contemporary systems thinking offer to logistics management as a management discipline, European Journal of Purchasing and Supply Management, Vol. 3,No. 2, 77-81.

[29]. McKinnon, A.C. (1989) Physical distribution systems. London: Routledge.

[30]. McKinnon, A.C. (1998) "Scottish brewers: The restructuring of a depot system", in: D. Taylor, ed., Global cases in logistics and supply chain management. London: International Thomson BusinessPress.

[31]. McKinnon, A.C. (1999) "The outsourcing of logistical activities", in: D. Waters, ed., Global logisticsand distribution planning: Strategies for management, 3rd edn. London: Kogan Page.

[32]. McKinnon, A.C. and Woodburn (1996) "Logistical restructuring and freight traffic growth: Anempirical assessment", Transportation, 23(2):141-161.

[33]. Morgan, G. A. (2004). SPSS for introductory statistics: Use and Interpretation. Mahwah, NJ: Lawrence Erlbaum Associates.

[34]. Nancy, L., Karen, B., \& George, M. (2005). SPSS for Intermediate Statistics (2nd ed.). Mahwah, New Jersey: Lawrence Erlbaum Associates, Publishers.

[35]. Polman, P. (2008). Unilever sustainable development overview 2008: highlights. Sustainable Development $2008:$ An overview, 36.

[36]. Rushton, A., Croucher, P., \& Baker, P. (2006). The handbook of Logistics and Distribution (3rd ed.). london, United Kingdom: Kogan Page.

[37]. Scott, C. and R. Wesbrook, (1991) "New strategic tools for supply chain management", InternationalJournal of Physical Distribution and Logistics Management, 21:23-33.

[38]. Somuyiwa, A.O (2010) Analysis of Logistics cost in the Supply Chain Management of manufacturing companies in Southwestern Nigeria, 2002-2006,published Ph.D Thesis, OlabisiOnabanjo University, Ago-Iwoye.

[39]. Stevens, G.C. (1989) "Integrating the supply chain”, International Journal of Physical Distribution andLogistics Management, 19:38.

[40]. Stewart, W. (1965) "Physical distribution: Key to improved volume and profits", Journal of Marketing,29:65-70.

[41]. Unilever Bangladesh Ltd. (2004). Merchandising. In Ershad-ul.Haque (Ed.),Merchandising development skill ,24 slides. Dhaka.

[42]. Unilever Nigeria Plc. (2011).Sales management and process. In Peter, Adeagbo(Ed.), Better salesmen in Nigeria : An overview, 13 slides. Lagos.

[43]. Unilever Philippines.(2005). CEF Module 1 Roles \& Responsibility. In B. d. Cruz(Ed.), TDOM, Workshop(Manila), 13 slides. 